\title{
Abstract \\ Gas-Phase Chemical Imaging System by Biofluorometry for Human VOCs Measurement ${ }^{\dagger}$
}

\author{
Kenta Iitani (1), Koji Toma (D), Takahiro Arakawa (1) and Kohji Mitsubayashi * \\ Institute of Biomaterials and Bioengineering, Tokyo Medical and Dental University, 2-3-10 Kanda-Surugadai, \\ Chiyoda-ku, Tokyo 101-0062, Japan; i.bdi@tmd.ac.jp (K.I.); toma.bdi@tmd.ac.jp (K.T.); \\ arakawa.bdi@tmd.ac.jp (T.A.) \\ * Correspondence: m.bdi@tmd.ac.jp \\ + Presented at the 8th International Symposium on Sensor Science, 17-28 May 2021; Available online: \\ https://i3s2021dresden.sciforum.net/.
}

check for updates

Citation: Iitani, K.; Toma, K.; Arakawa, T.; Mitsubayashi, K. Gas-Phase Chemical Imaging System by Biofluorometry for Human VOCs Measurement. Eng. Proc. 2021, 6, 73. https://doi.org/10.3390/ I3S2021Dresden-10181

Academic Editors: Gianaurelio Cuniberti and Larysa Baraban

Published: 25 May 2021

Publisher's Note: MDPI stays neutral with regard to jurisdictional claims in published maps and institutional affiliations.

Copyright: (c) 2021 by the authors. Licensee MDPI, Basel, Switzerland. This article is an open access article distributed under the terms and conditions of the Creative Commons Attribution (CC BY) license (https:// creativecommons.org/licenses/by/ $4.0 /)$.

\begin{abstract}
Many gas-phase biosensors have been developed for human volatiles (acetone, methyl mercaptan, trimethylamine, ethanol, isopropanol, etc.) and for residential harmful VOCs (formaldehyde, toluene, nicotine) causing some diseases. A novel gas-imaging system by biofluorometry with an enzyme immobilized mesh was investigated to demonstrate spatiotemporal gas-imaging for human volatiles (i.e., ethanol and acetaldehyde after drinking). A biofluorometric technique was applied to improve the performance (sensitivity, calibration range, gas-selectivity, etc.) of the gas-imaging system. The biofluorometric sniff-cam for ethanol was fabricated with an ADH (alcohol dehydrogenase) immobilized mesh and an NADH fluorescent visualization unit (UV-LED sheet array and highly sensitive camera); thus, showing the two-dimensional real-time imaging of ethanol vapor distribution (0.5-200 ppm). The system showed rapid and accurate responses and a visible measurement of ethanol in the gas phase. The intensity of fluorescence was linearly related to the concentration of ethanol vapor. The high sensitivity fluorescent imaging of ethanol vapor allows to successfully visualize gaseous ethanol from the human body (exhaled air and skin gas) after drinking. The sniff-cam system would be useful for the conventional detecting and imaging of the volatile biomarkers.
\end{abstract}

Keywords: gas-imaging system; biofluorometry; enzyme; exhaled air; skin gas; LED; camera

Institutional Review Board Statement: The study was conducted according to the guidelines of the Declaration of Helsinki, and approved by the Ethics Committee of Tokyo Medical and Dental University (protocol code M2018-160, 14 December 2018 to 31 March 2024).

Informed Consent Statement: Informed consent was obtained from all subjects involved in the study. Data Availability Statement: Not applicable. 